\title{
Comparative analysis of the complete genome of an epidemic hospital sequence type 203 clone of vancomycin-resistant Enterococcus faecium
}

Margaret MC Lam ${ }^{1,5}$, Torsten Seemann², Nicholas J Tobias' ${ }^{1}$, Honglei Chen ${ }^{3}$, Volker Haring ${ }^{3}$, Robert J Moore ${ }^{3,4}$, Susan Ballard ${ }^{5}$, Lindsay M Grayson ${ }^{5,6}$, Paul DR Johnson ${ }^{1,5,6}$, Benjamin P Howden ${ }^{1,5,7,8}$ and Timothy P Stinear ${ }^{1,8^{*}}$

\begin{abstract}
Background: In this report we have explored the genomic and microbiological basis for a sustained increase in bloodstream infections at a major Australian hospital caused by Enterococcus faecium multi-locus sequence type (ST) 203, an outbreak strain that has largely replaced a predecessor ST17 sequence type.

Results: To establish a ST203 reference sequence we fully assembled and annotated the genome of Aus0085, a 2009 vancomycin-resistant Enterococcus faecium (VREfm) bloodstream isolate, and the first example of a completed ST203 genome. Aus0085 has a 3.2 Mb genome, comprising a $2.9 \mathrm{Mb}$ circular chromosome and six circular plasmids (2 kb-130 kb). Twelve percent of the 3222 coding sequences (CDS) in Aus0085 are not present in ST17 E. faecium Aus0004 and ST18 E. faecium TX16. Extending this comparison to an additional 12 ST17 and 14 ST203 E. faecium hospital isolate genomes revealed only six genomic regions spanning $41 \mathrm{~kb}$ that were present in all ST203 and absent from all ST17 genomes. The 40 CDS have predicted functions that include ion transport, riboflavin metabolism and two phosphotransferase systems. Comparison of the vancomycin resistance-conferring Tn 1549 transposon between Aus0004 and Aus0085 revealed differences in transposon length and insertion site, and van locus sequence variation that correlated with a higher vancomycin MIC in Aus0085. Additional phenotype comparisons between ST17 and ST203 isolates showed that while there were no differences in biofilm-formation and killing of Galleria mellonella, ST203 isolates grew significantly faster and out-competed ST17 isolates in growth assays.

Conclusions: Here we have fully assembled and annotated the first ST203 genome, and then characterized the genomic differences between ST17 and ST203 E. faecium. We also show that ST203 E. faecium are faster growing and can out-compete ST17 E. faecium. While a causal genetic basis for these phenotype differences is not provided here, this study revealed conserved genetic differences between the two clones, differences that can now be tested to explain the molecular basis for the success and emergence of ST203 E. faecium.
\end{abstract}

Keywords: Vancomycin resistant enterococci, VRE, Sequence type 203, Antibiotics, Whole genome, Transposon, Nosocomial

\footnotetext{
* Correspondence: tstinear@unimelb.edu.au

'Department of Microbiology and Immunology, University of Melbourne,

Parkville 3010, Victoria, Australia

${ }^{8}$ Department of Microbiology, Monash University, Clayton, Victoria 3800,

Australia

Full list of author information is available at the end of the article
}

\section{Biomed Central}

(c) 2013 Lam et al.; licensee BioMed Central Ltd. This is an Open Access article distributed under the terms of the Creative Commons Attribution License (http://creativecommons.org/licenses/by/2.0), which permits unrestricted use, distribution, and reproduction in any medium, provided the original work is properly cited. 


\section{Background}

Enterococci are part of the human gastrointestinal tract microbiota but some species within the genus are also significant opportunistic nosocomial pathogens [1]. Enterococcal infections can be difficult to treat because of their intrinsic and acquired resistance to many classes of antibiotics, including what are often considered last-line agents such as vancomycin and daptomycin [2,3]. The difficulties associated with treatment, coupled with the risk of cross transmission to other patients, make enterococcal infections a significant infection control issue in hospitals [1].

Enterococci that are resistant to vancomycin are collectively referred to as vancomycin-resistant enterococci (VRE) [4,5]. Vancomycin resistance is conferred by the presence of one of nine different gene clusters, although the majority of VRE strains possess either the van $A$ or $\operatorname{van} B$ operon [6-8]. Enterococcus faecium and Enterococcus faecalis are the two enterococci most frequently causing human infections, however vancomycin resistance has become increasingly common predominately in E. faecium, in the past two decades $[9,10]$. The first reported cases of VRE occurred in Europe and the UK in the 1980s and VRE has since been reported in hospitals worldwide [11,12]. In Australia, the first known case of VRE was reported at the Austin Hospital in 1994 [13]. VRE has since emerged Australia-wide and a number of Australian hospitals have experienced VRE outbreaks, predominantly involving colonization in the clinical environment [14]. In contrast to the United States where vanA-type resistance predominates, vanB-type vancomycin resistant $E$. faecium are the most important cause of VRE infections in Australia [15].

Molecular epidemiology of E. faecium has been based primarily on pulsed field gel electrophoresis (PFGE) and multi-locus sequence typing (MLST) [16,17]. MLST has revealed the emergence of related lineages called clonal complex 17 (CC17), which comprise strains associated with hospital infections across at least five continents [18]. Many of these hospital strains have acquired resistance to ampicillin and quinolones, and their genomes contain a high number of mobile genetic elements that distinguish them from community-acquired and non-pathogenic strains [18-20].

We have previously reported on a significant increase in cases of $E$. faecium bacteraemia at a major Australian Hospital. MLST of the E. faecium isolates collected from bacteraemic patients over a 12-year period revealed a replacement of CC17 sequence type 17 (ST17) strains, with emergent CC17 ST203 isolates [14]. A survey evaluating the incidence of VRE and vancomycin-susceptible enterococci (VSE) in Australia from 2005 to 2010, conducted by the Australian Group on Antimicrobial Resistance (AGAR) in collaboration with participating microbiology labs, showed a marked increase in VRE rates throughout Australia. Reflecting the very same trends observed at Austin Health, the majority of these Australian VRE strains not only possessed the $\operatorname{van} B$ gene but were also ST203 [21]. In our initial study we compared partially assembled genome sequences for representative ST17 (Aus0004) and ST203 (Aus0085) VRE isolates and showed $500 \mathrm{~kb}$ of unique DNA differentiating the two [14]. We also recently established and analysed the complete genome sequence of E. faecium ST17 Aus0004 as a basis for a more thorough genome comparison [22].

In this current study, genome and phenotype comparisons were performed to explore in more detail the differences between 13 ST17 and 15 ST203 E. faecium isolates to help explain the emergence of ST203 and its success as an opportunistic hospital pathogen. We fully assembled and annotated the genome of E. faecium ST203 Aus0085, the first complete ST203 reference sequence, and compared it with the recently fully assembled and annotated genomes of ST17 Aus0004 and ST18 isolate TX16 [22,23]. Growth rates and biofilm formation were also measured for a collection of ST17 and ST203 isolates, and virulence was assessed in the Greater Wax Moth (Galleria mellonella) invertebrate model.

\section{Results}

\section{Enterococcus faecium Aus00085 genome summary}

The genome of E. faecium Aus0085 is comprised of a single circular chromosome $(2,994,661 \mathrm{bp})$ with a GC content of $38.2 \%, 2,922$ protein-coding DNA sequences (CDS), 75 tRNA genes, and 6 rRNA operons. Comparisons of an in silico NcoI map of the fully-assembled Aus0085 chromosome sequence against the Aus0085 Ncol optical map confirmed the accuracy of the chromosome assembly (Figure 1A). Aus0085 also harbors six circular plasmids, Aus0085_p1, Aus0085_p2, Aus0085_p3, Aus0085_p4, Aus0085_p5 and Aus0085_p6, with lengths of $130,716 \mathrm{bp}, 67,314 \mathrm{bp}, 31,004 \mathrm{bp}, 9,319 \mathrm{bp}, 4,072 \mathrm{bp}$, 2,189 bp respectively.

\section{Comparative genomics of Aus0085 E. faecium}

The chromosome features for ST203 E. faecium Aus0085 were compared with ST17 E. faecium Aus0004 and another recently closed E. faecium genome, TX16 (Table 1). Chromosome alignments indicated significant conservation of genome architecture between the three isolates. The large chromosome inversion seen in Aus0004 is not present in Aus0085 and TX16 (Figure 1B). DNA comparisons and ortholog cluster analysis showed that E. faecium Aus0085 possesses at least 8 chromosomal segments spanning approximately $224 \mathrm{~kb}$ that are not present in both Aus0004 and TX16, and an additional four regions spanning $133 \mathrm{~kb}$ that are absent in Aus0004 but present in TX16. These Aus0085 'specific' regions include four distinct prophage, and loci involved in metabolic functions 


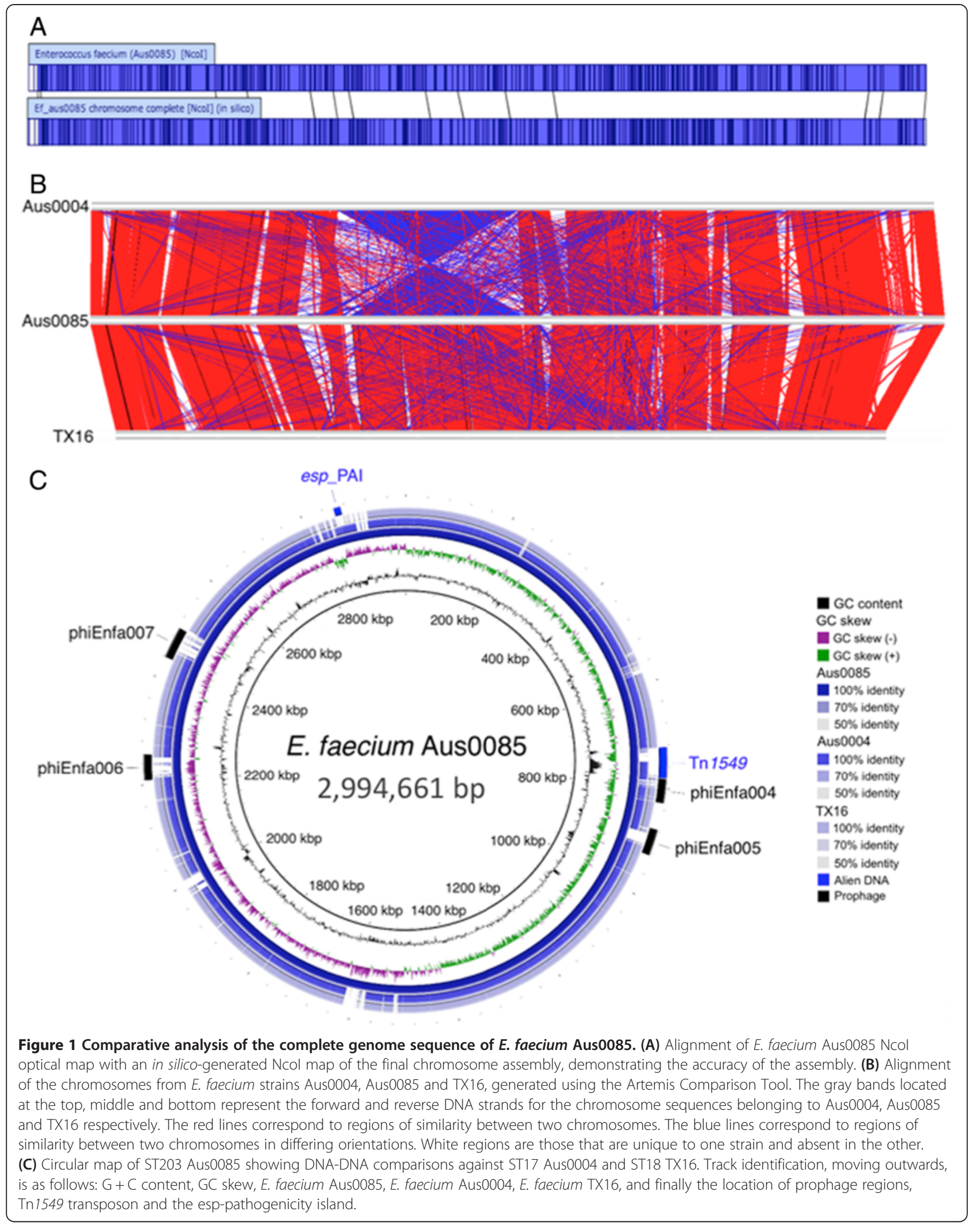


Table 1 Genome comparisons between E. faecium strains Aus0004 (ST17), Aus0085 (ST203) and TX16

\begin{tabular}{llll}
\hline & ST17 Aus0004 & ST203 Aus0085 & ST18 TX16 \\
\hline Chromosome size (G+ C\%) & 2,955,294 bp (38.4\%) & 2,994,661 bp (38.2\%) & 2,698,137 bp (38.15\%) \\
\hline Plasmids (size, G + C\%) & Aus0004_p1 (56,520 bp, 35.4\%) & Aus0085_p1 (130,716 bp, 34.9\%) & pDO1 (36,262 bp, 36.51\%) \\
& Aus0004_p2 (4,119 bp, 36.8\%) & Aus0085_p2 (67,314 bp, 35.2\%) & pDO2 (66,247 bp, 34.38\%) \\
& Aus0004_p3 (3,847 bp, 39.0\%) & Aus0085_p3 (31,004 bp, 34.6\%) & pDO3 (251,926 bp, 35.97\%) \\
& & Aus0085_p4 (9,319 bp, 30.9\%) & \\
& & Aus0085_p5 (4,072 bp, 36.2\%) & 3,114 \\
\hline CDS & Aus0085_p6 (2,189 bp, 38.9\%) & \\
\hline rRNA operons & 6,932 & 3,222 & 64 \\
\hline tRNA & 6 & 6 & \\
\hline
\end{tabular}

such as carbohydrate utilization and metal ion transport. A complete list of Aus0085 genes not present in Aus0004 or TX16 is provided see (Additional file 1: Table S1).

To refine this comparative analysis, whole genome sequence reads obtained from an additional 12 ST17 and 14. ST203 previously described hospital isolates were mapped to the Aus0085 chromosome. Seven distinct regions of difference were identified, spanning $41 \mathrm{~kb}$ and 40 genes found in all 15 ST203 isolates but absent from the ST17 collection (Figure 2A). The majority of these genes encoded proteins with functions related to metabolism including riboflavin biosynthesis (Ef_aus0085_01495), gene regulation (Ef_aus0085_00243, Ef_aus0085_01493, Ef_aus0085_02507, Ef_aus0085_02509), metal ion transport (Ef_aus0085_00246) and phosphotransferase systems (Ef_aus0085_02768, Ef_aus0085_02779) (Figure 2A and Additional file 2: Table S2).

Read-mapping also permitted delineation of a core genome, revealing 2,217,189 bases, (Aus0085 genome: $75 \%$ core and $25 \%$ accessory) that were present in all $28 \mathrm{E}$. faecium genomes. Pairwise comparisons of the Aus0085 core genome sequence with the core genomes of the other isolates uncovered 9865 variable nucleotide positions (including substitutions and indels). A distance matrix was prepared and a robust phylogeny was inferred by both split decomposition analysis and neighbor-joining methods that highlighted the substantial nucleotide differences between ST203 and ST17 isolates (Figure 2B). A reticulated phylogeny was observed by split decomposition, indicating likely recombination among this collection of $E$. faecium (data not shown). These substantial clone-specific differences were then confirmed by independent in silico analysis. De novo assembly with gene and protein prediction of the $26 \mathrm{E}$. faecium genomes (Table 2), followed by ortholog clustering that also included Aus0085 and Aus0004 based on MLST category, confirmed the same 40 ST203-specific genes as identified by read-mapping (Figure 2C, Additional file 2: Table S2).
The two MLST groups shared 1247 genes, while there were 31 genes specific to the ST17 isolates (Figure 2C, Additional file 2: Table S2).

\section{The Aus0085 genome is largely comprised of mobile genetic elements}

Like Aus0004 and TX16, a large proportion of the genome for Aus0085 is comprised of mobile genetic elements. A total of 91 insertion sequence elements (ISEs), representing twenty different types of ISEs, were identified. The copy numbers of the ISEs varied from 1 to 24 . The most frequently occurring ISE differed between Aus0004 (ISEf1, 13 copies) and Aus0085 (ISEfa5, 24 copies). Four distinct prophage were identified in Aus0085 including, phiEnfa004 (782514-827419), phiEnfa005 (876860-925798), phiEnfa006 (2208334-2256786) and phiEnfa007 (2439241-2497696). The Aus0085 prophage are distinct to the prophage regions present in Aus0004 and TX16, although as demonstrated in Figure 1C, many of the CDS that make up phiEnfa004 also appear in the other two genomes, which suggests this prophage is reasonably conserved. Interestingly, the two CRISPR-associated proteins present in the prophages phiEnfa001 and phiEnfa002 in Aus0004 are not present in Aus0085, and no other CRISPR loci were detected in Aus0085.

\section{The Tn1549-like vanB-containing transposon in Aus0085} is distinct from Aus0004

A single copy of a Tn1549-like transposon, encoding vanB-type vancomycin resistance, was present in the Aus0085 chromosome, inserted within a signal peptidase I gene (EFAU085_00682) between nucleotide positions 723825-781312, which is different from the insertion site in Aus0004 (Figure 1C). Comparisons of Tn1549 between Aus0004 and Aus0085 revealed a conserved 30 $\mathrm{kb}$ core (Figure 3A). However, Tn1549 in Aus0085 is significantly larger, containing an additional $23.7 \mathrm{~kb}$ with 20 CDS that appear to encode another conjugative 


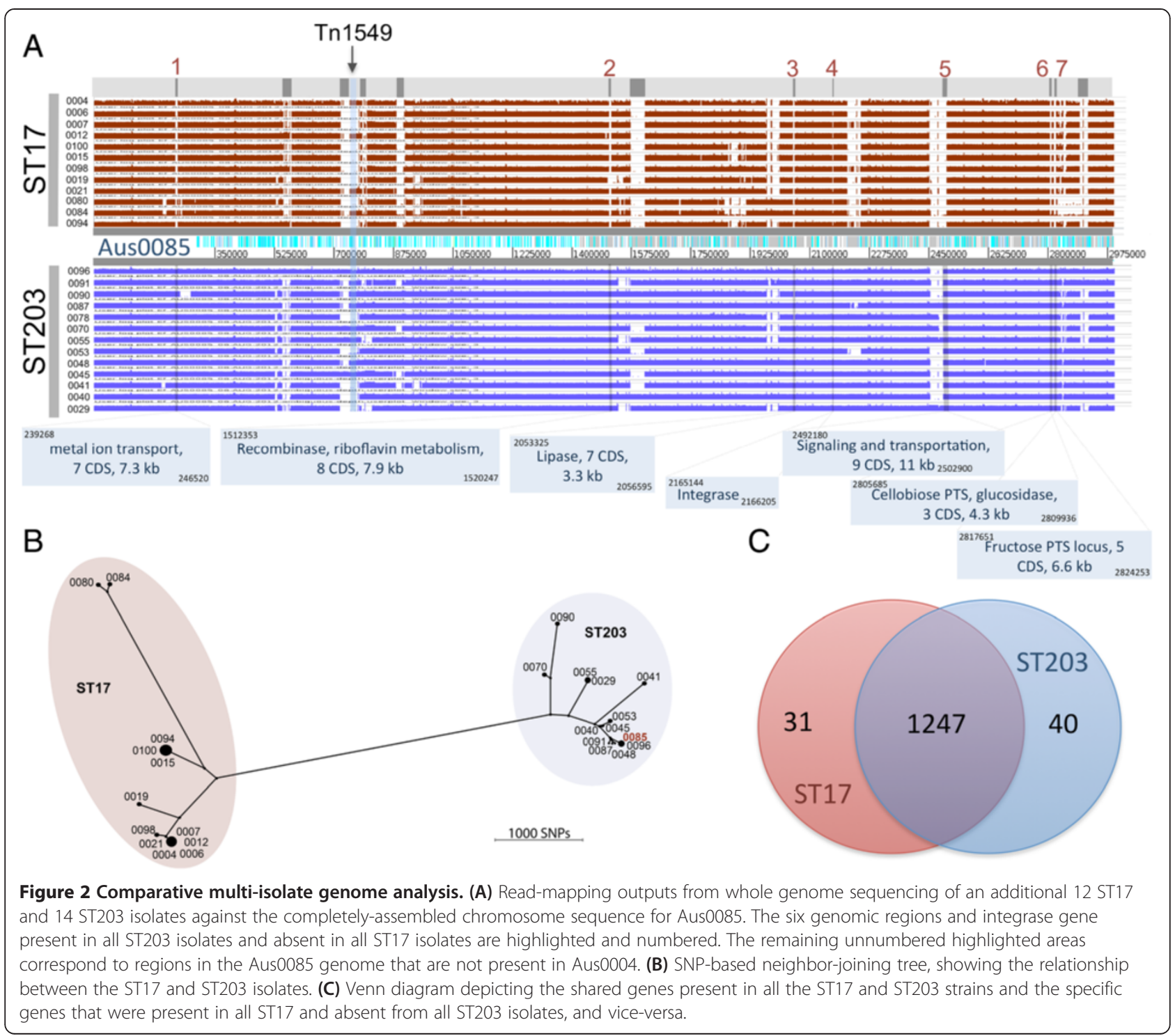

transfer system (Table 3). When Tn1549 excises from its chromosomal location, it can take $4-6$ bp of flanking sequence from the donor DNA that is then incorporated in the recipient at the site of insertion [24]. Different donor sequences (also called coupling sequences) were observed between Aus0004 and Aus00085, which together with the different form of Tn1549 indicate a different source of this transposon for each isolate (Figure 3B). The van locus in Aus0085 was differentiated from the Aus0004 version by 2 non-conservative amino acid substitutions that may impact function located within the histidine kinase domain of VanS (E251G) and the N-terminal substrate-binding domain of VanB (C101F). Interestingly, the vancomycin minimal inhibitory concentration (MIC) for Aus0004 was $12 \mathrm{mg} / \mathrm{L}$ compared with $256 \mathrm{mg} / \mathrm{L}$ for Aus0085.

\section{Additional plasmids in Aus0085 contribute to the Aus0085-specific genome}

Aus0085 harbors six plasmids, compared to three plasmids in Aus0004. The increased number of plasmids adds an additional $180 \mathrm{~kb}$ to the Aus0085 genome, with plasmid sizes ranging from $2.2 \mathrm{~kb}$ to $130.7 \mathrm{~kb}$. Table $4 \mathrm{con}-$ tains a summary of the predicted functions of plasmid CDS. Comparisons of the plasmid sequences in Aus0085 against the genome sequences from other enterococci show that the majority of sequence and CDS in the Aus0085 plasmids are also present in plasmids from E. faecium (including Aus0004), E. faecalis and other enterococcal species as well as other species from other genera such as Staphylococcus and Streptococcus. Plasmid comparisons between Aus0004 and Aus0085 reveal that Aus0085_p2 is highly related (99\% sequence identity) to Aus0004_p1, a 
Table 2 E. faecium strains used in this study

\begin{tabular}{|c|c|c|c|}
\hline Strain & Year of isolation & MLST sequence type & van type \\
\hline Aus0004 & 1998 & ST17 & $\operatorname{van} B$ \\
\hline Aus0006 & 1999 & ST17 & $-{ }^{*}$ \\
\hline Aus0007 & 1999 & ST17 & - \\
\hline Aus0012 & 2000 & ST17 & $\operatorname{van} B$ \\
\hline Aus0100 & 2000 & ST17 & - \\
\hline Aus0015 & 2002 & ST17 & - \\
\hline Aus0098 & 2003 & ST17 & - \\
\hline Aus0019 & 2004 & ST17 & - \\
\hline Aus0021 & 2004 & ST17 & $\operatorname{van} B$ \\
\hline Aus0026 & 2005 & ST17 & - \\
\hline Aus0029 & 2005 & ST203 & - \\
\hline Aus0040 & 2006 & ST203 & - \\
\hline Aus0041 & 2006 & ST203 & - \\
\hline Aus0043 & 2006 & ST203 & - \\
\hline Aus0045 & 2007 & ST203 & $\operatorname{van} B$ \\
\hline Aus0048 & 2007 & ST203 & $\operatorname{van} B$ \\
\hline Aus0053 & 2007 & ST203 & - \\
\hline Aus0055 & 2007 & ST203 & $\operatorname{van} B$ \\
\hline Aus0070 & 2008 & ST203 & $\operatorname{van} B$ \\
\hline Aus0078 & 2008 & ST203 & - \\
\hline Aus0080 & 2008 & ST17 & - \\
\hline Aus0084 & 2009 & ST17 & $\operatorname{van} B$ \\
\hline Aus0085 & 2009 & ST203 & $\operatorname{van} B$ \\
\hline Aus0087 & 2009 & ST203 & $\operatorname{van} B$ \\
\hline Aus0090 & 2009 & ST203 & $\operatorname{van} B$ \\
\hline Aus0091 & 2009 & ST203 & $\operatorname{van} B$ \\
\hline Aus0096 & 2009 & ST203 & $\operatorname{van} B$ \\
\hline Aus0094 & 2009 & ST17 & - \\
\hline
\end{tabular}

*indicates strains that are vancomycin-susceptible isolates, which therefore do not possess the van operon.

$56.5 \mathrm{~kb}$ plasmid present in Aus0004, although Aus0085_p2 is $10.8 \mathrm{~kb}$ longer. Additionally, Aus0085_p5 is closely related to Aus0004_p3. The smallest plasmid Aus0085_p6 $(2.2 \mathrm{~kb})$, which has no other CDS other than that encoding the replication initiation protein, possesses three regions (nucleotide positions 1-938, 1182-1608 and 1982-2189) that share significant sequence identity $(80 \%, 92 \%$ and $85 \%$ respectively) to the cryptic plasmid pRI1 [25].

A total of $99 \mathrm{CDS}$, which represents one-third of the CDS that makes up the $245 \mathrm{~kb}$ plasmid sequence in Aus0085, are not present in Aus0004, and some of these genes are candidates to explain the growth and antimicrobial susceptibility differences between ST17 and ST203 isolates. With the exception of EFAU085_p2057, which encodes a hypothetical protein that is found only in Aus0085, all the other Aus0085 CDS that do not appear in Aus0004 are present in the genomes belonging to other E. faecium isolates or other enterococcal species. Among the plasmid CDS that have been assigned a function, several encode important features that enhance the survival of Aus0085. Notably, the aadE-sat4-aphA gene cluster, reported in a number of multidrug-resistant $E$. faecium and E. faecalis strains, is present on plasmid Aus0085_p3. The genes in the aadE-sat4-aphA cluster confer resistance to three different antibiotics, streptomycin, streptothricin and kanamycin, respectively [26]. However, sat4 is disrupted by an ISE (EFAU085_p3014) and is therefore unlikely to be functional. The $\operatorname{aadE}$ and aphA genes are intact. Streptomycin MICs differed as predicted between Aus0004 and Aus0085, with values of $48 \mathrm{mg} / \mathrm{L}$ and $1024 \mathrm{mg} / \mathrm{L}$ respectively.

Other Aus0085 plasmid CDS that encode important features that are absent in Aus0004 include a PTS-lactose uptake system (lacG, lacE, lacF, lacD2, lacC, lacB, lacA) on Aus0085_p1, a bacterial extracellular solute-binding protein on Aus0085_p1 and additional toxin-antitoxin systems on plasmids Aus0085_p1 and Aus0085_p3. Interestingly, Aus0085_p1 possesses a citrate lyase complex (oadHDB-citCDEFX-oadA-citMG), which has been previously described in various Firmicutes including $E$. faecium and E. faecalis [27,28]. However, this locus may be non-functional as citC and citG are predicted pseudogenes. Additionally, the other auxiliary genes required for producing an active citrate lyase appear to be absent from Aus0085_p1.

\section{CDS associated with virulence}

The same putative enterococcal virulence factors identified in Aus0004 were also present in Aus0085. While the sequences of the genes encoding hemolysin (EFAU085_01000) and collagen-binding adhesin (acm; EFAU085_02356) were nearly identical to the corresponding genes in Aus0004 (99-100\% identity). The enterococcal surface protein (esp) encodes a 1733 aa protein with a likely role in colonization $[29,30]$. The Aus0085 esp gene (EFAU085_2821) has an additional $264 \mathrm{bp}$ representing an extra copy of one of its 3 ' tandem repeats compared to the Aus0004 ortholog.

Bacteriocins are small protein pore-forming toxins produced by certain bacteria that can prevent the growth of closely related strains $[31,32]$. We therefore compared the bacteriocin gene content of Aus0085 with Aus0004 to see if additional bacterioicin-like genes might explain the emergence of Aus0085. However genome comparisons showed no novel bacteriocins in Aus0085 and both isolates shared the same complement of three bacteriocin genes (>99\% nt identity between each clone), although their genome location varied. For example a gene encoding a lactococcin 972-like protein is present on Aus0085 plasmid 


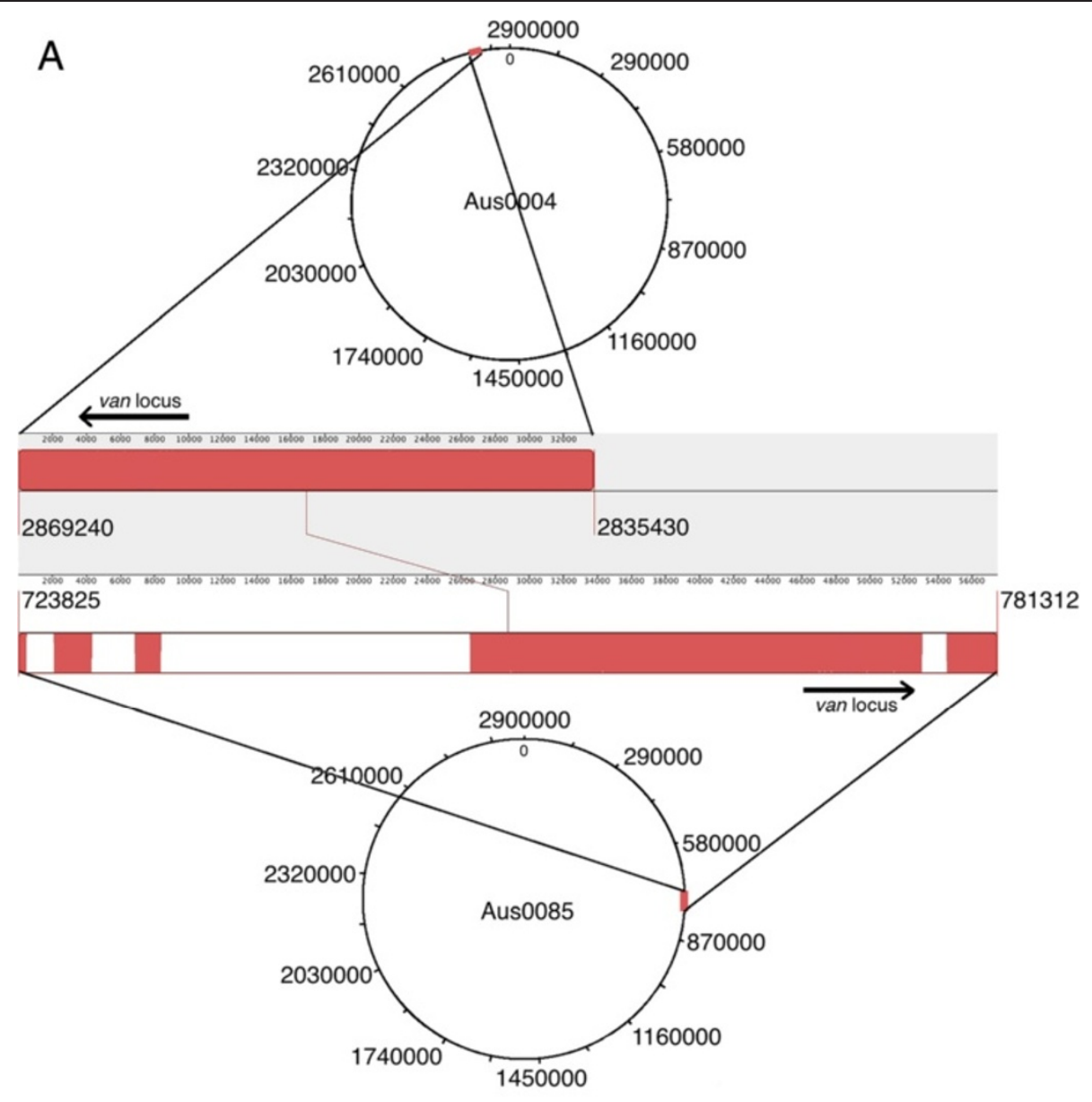

$\mathrm{B}$

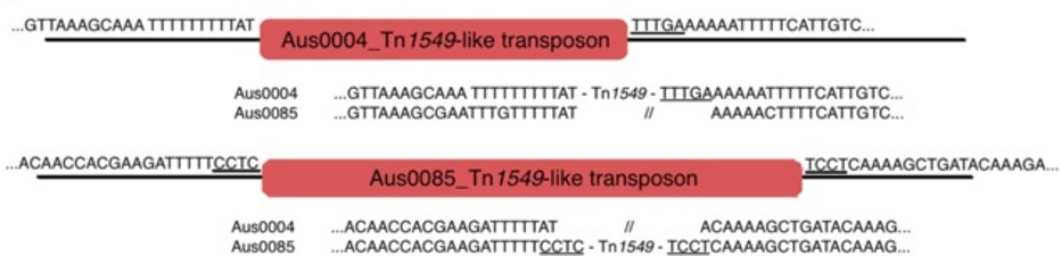

Figure 3 Analysis of Tn1549. (A) Chromosomal location and alignment of Tn1549 from E. faecium isolates Aus0004 (nucleotide positions 2835430-2869240) and Aus0085 (nucleotide positions 723825-781312, reverse orientation). Compared to Tn1549 in Aus0004, the element in E. faecium Aus0085 is $23.7 \mathrm{~kb}$ longer. White regions correspond to the unique $23.7 \mathrm{~kb}$ sequence. The red regions correspond to matches between the two transposons. (B) Transposon insertion site comparisons showing the left-hand side and right-hand side flanking regions and donor (coupling) sequences.

P4 (EFAU085_p4005) but on the chromosome in Aus0004 (EFAU004_00292).

\section{E. faecium ST203 isolates grow more quickly than ST17}

To determine whether there were any differences in growth rates between different isolates, which might be linked to the additional metabolic genes or the lactose metabolism pathway identified in the genome for ST203-representative strain Aus0085, we conducted growth curve experiments to compare doubling times between the ST17 and ST203 strains. Exponential phase doubling times were calculated and a significant difference $(\mathrm{p}=0.0304)$ was observed between ST17 (average: $55.186 \mathrm{~min}, \mathrm{SD}: 8.216 \mathrm{~min}$ ) and ST203 isolates (average: $48.136 \mathrm{~min}, \mathrm{SD}: 7.611 \mathrm{~min}$ ) (Figure 4). The doubling times for the two sequenced strains were not different; Aus0004 possessed an average doubling time of 66.1 minutes while average doubling time for Aus008 was 65.3 minutes. 


\begin{tabular}{|c|c|c|}
\hline $\begin{array}{l}\text { Locus tag in } \\
\text { Aus } 0085\end{array}$ & $\begin{array}{l}\text { Nucleotide } \\
\text { position }\end{array}$ & CDS, predicted product \\
\hline EFAU085_00684 & 724423 to 725631 & IS110, transposase \\
\hline EFAU085_00689 & 728728 to 730545 & $\begin{array}{l}\text { HNH endonuclease } \\
\text { domain protein }\end{array}$ \\
\hline EFAU085_00692 & 732291 to 732638 & Hypothetical protein \\
\hline EFAU085_00693 & 732653 to 732934 & Hypothetical protein \\
\hline EFAU085_00694 & 733193 to 733975 & RNase II stability modulator \\
\hline EFAU085_00695 & 734148 to 735866 & $\mathrm{Na}+/ \mathrm{Pi}$ - cotransporter \\
\hline EFAU085_00696 & 735868 to 736722 & Phosphate binding protein \\
\hline EFAU085_00697 & 736688 to 736801 & Hypothetical protein \\
\hline EFAU085_00698 & 737419 to 737718 & Hypothetical protein \\
\hline EFAU085_00699 & 737742 to 738152 & Single strand binding protein \\
\hline EFAU085_00700 & 738299 to 738505 & Putative transcriptional regulator \\
\hline EFAU085_00701 & 738852 to 739373 & TDP-fucosamine acetyltransferase \\
\hline EFAU085_00702 & 739431 to 739856 & Acetyltransferase, GNAT family \\
\hline EFAU085_00703 & 740299 to 740481 & Hypothetical protein \\
\hline EFAU085_00704 & 740594 to 742105 & Hypothetical protein \\
\hline EFAU085_00705 & 742428 to 742652 & Hypothetical protein \\
\hline EFAU085_00706 & 742645 to 743211 & Hypothetical protein \\
\hline EFAU085_00707 & 743199 to 743429 & Hypothetical protein \\
\hline EFAU085_00708 & 743630 to 743995 & Hypothetical protein \\
\hline EFAU085_00709 & 743995 to 745722 & Conjugal transfer relaxase TraA \\
\hline EFAU085_00710 & 745761 to 747668 & Hypothetical protein \\
\hline EFAU085_00711 & 747933 to 748049 & Hypothetical protein \\
\hline EFAU085_00712 & 748353 to 748535 & Hypothetical protein \\
\hline EFAU085_00713 & 748562 to 750259 & $\begin{array}{l}\text { Resolvase family site-specific } \\
\text { recombinase }\end{array}$ \\
\hline EFAU085_00737 & 776918 to 777724 & ISEnfa3, transposase \\
\hline EFAU085_00738 & 777721 to 728257 & ISEnfa3, transposase \\
\hline
\end{tabular}

\section{E. faecium ST203 Aus0085 and Aus0090 out-competes} ST17

We next took advantage of the high-level gentamicin resistance of Aus0085 and Aus0090 and performed coculture experiments to assess whether these representative ST203 isolates could outcompete ST17 isolates. As indicated by the relative competitive fitness index (RCFI) (Figure 5), both ST203 isolates out-competed the ST17 isolates, Aus0004 and Aus0021, by approximately the same factor. Statistical analysis showed all comparisons were significantly higher than the threshold RCFI value of 1. Aus0004, Aus0021 and Aus0085 possessed similar doubling times of 66.068, 64.282 and 65.341 minutes respectively. However, compared to the other strains, Aus0004 took, on average, two hours longer to reach stationary phase, and Aus0090 had a significantly faster doubling time of 52.942 minutes.
Biofilm formation is not an E. faecium clone-specific trait The ability of E. faecium to form biofilms is thought to be an important phenotype with respect to virulence traits such as colonization, environmental persistence and antibiotic resistance [33-35]. We therefore performed biofilm assays to determine whether a difference in biofilm formation abilities distinguished the two ST clones. Three E. faecium ST17 strains Aus0006, Aus0019 and Aus0094 showed enhanced biofilm-forming capacity compared to the other isolates $(\mathrm{p}<0.05)$ but no relationship with sequence type was observed (Figure 6).

\section{Virulence is a heterogeneous phenotype in both the ST17 and ST203 strains}

We examined survival rates of G. mellonella larvae after inoculation with ST17 and ST203 E. faecium. The Kaplan Meier plots were analysed to compare virulence between isolates see (Additional file 3: Figure S1 and Additional file 4: Figure S2 for the individual Kaplan Meier survival plots generated for each of the ST17 and ST203 isolates, respectively). Based on observations made during the experiments, isolates were considered virulent if all larvae within a group died within three days of inoculation. Virulence varied independent of sequence type (Figure 7). However, excluding Aus0087, which exhibited small colony variant morphology, the ST203 strains isolated from 2009 onwards, killed G. mellonella larvae within three days. Larvae inoculated with small colony variant strains Aus0041, Aus0078 and Aus0087 exhibited increased survival rates. The number of bacteria present in the larvae at the time of death was also quantified, with values ranging from $2.2 \times 10^{6} \mathrm{CFU} / \mathrm{ml}$ to $4.25 \times 10^{8} \mathrm{CFU} / \mathrm{ml}$. Substantial variations were observed in CFU, even in larvae that had been inoculated with the same isolate, suggesting that differences in growth between different sequence types does not explain the rate at which the larvae are killed.

\section{Discussion}

Nosocomial outbreaks of E. faecium are now dominated by ST203 in Australia, and this ST has also been responsible for nosocomial outbreaks in Germany and China $[36,37]$. However, surprisingly little is known about this group of clones or why it emerged almost simultaneously in several hospitals and Australian states. Additionally, the apparent shift from ST17 E. faecium to ST203 observed at the Austin Hospital is reflected in a previous study that examined the population structure of E. faecium. Hospital isolates can be categorized into two groups (BAP2-1 and BAP3-3) [38], with ST17 isolates belonging to BAP3-3 and ST203 isolates belonging to BAP2-1. These observations correlate with the trends observed at the Austin Hospital and in hospitals around Australia, where strains belonging to BAP3-3 dominated from 1990 to 2004, and 
Table 4 Description of plasmids present in E. faecium strain Aus0085

\begin{tabular}{|c|c|c|c|c|c|c|}
\hline & Aus0085_p1 & Aus0085_p2 & Aus0085_p3 & Aus0085_p4 & Aus0085_p5 & Aus0085_p6 \\
\hline Length & $130,716 \mathrm{bp}$ & $67,314 \mathrm{bp}$ & $31,004 \mathrm{bp}$ & $9,319 \mathrm{bp}$ & $4,072 \mathrm{bp}$ & $2,189 \mathrm{bp}$ \\
\hline GC content & $34.9 \%$ & $35.2 \%$ & $34.6 \%$ & $30.9 \%$ & $36.2 \%$ & $38.9 \%$ \\
\hline Rep family & 2 & 17 & 2 & Unique & 14 & 14 \\
\hline No. of CDS & 162 & 78 & 42 & 12 & 5 & 1 \\
\hline \multirow[t]{3}{*}{ Comments } & \multirow{2}{*}{$\begin{array}{l}\text { *F.O.I: genes related to } \\
\text { lactose metabolism } \\
\text { (p1096 to p1 105), } \\
\text { citrate metabolism } \\
\text { (p1074 to p1084) }\end{array}$} & \multirow[t]{3}{*}{$\begin{array}{l}\text { Similar to } \\
\text { Aus0004_p1. }\end{array}$} & $\begin{array}{l}\text { F.O.I: toxin-antitoxin } \\
\text { system (p3009 and p3010) }\end{array}$ & \multirow{3}{*}{$\begin{array}{l}\text { F.O.I: bacteriocin, } \\
\text { lactococcin } \\
972 \text { family }\end{array}$} & \multirow[t]{3}{*}{$\begin{array}{l}\text { Similar to } \\
\text { Aus0004_p3 }\end{array}$} & \multirow{3}{*}{$\begin{array}{l}\text { Comprised of only } \\
\text { a rep protein, similar } \\
\text { to cryptic plasmid pRI1 }\end{array}$} \\
\hline & & & $\begin{array}{l}\text { aphA, sat4, aadE aminoglycoside } \\
\text { resistance (p3013, p3015 and p3016) }\end{array}$ & & & \\
\hline & $\begin{array}{l}\text { Toxin-antitoxin sytem } \\
\text { (p1087 to p1090) }\end{array}$ & & $\begin{array}{l}\text { Lincosamide } \\
\text { nucleotidyltransferase }\end{array}$ & & & \\
\hline
\end{tabular}

*F.O.I features of interest.

have been replaced with BAP2-1 isolates from 2005 onwards [14].

In this report, we have fully assembled and annotated the genome of strain Aus0085. To our knowledge, this is the first complete ST203 E. faecium genome sequence. Comparisons with the only two other complete $E$. faecium genomes, ST17 Aus0004 and ST18 TX16, were performed to understand the genetic basis behind the emergence and increase in ST203 VRE. Comparative analysis revealed $502 \mathrm{~kb}$ of sequence present only in Aus0085. These regions of difference spanned eight chromosomal segments in Aus0085 (including four distinct prophage) and four of the six plasmids harbored by this isolate. Genome comparisons were extended to a collection of ST17 and ST203 isolates and this reduced the amount of ST203 'unique' DNA to six chromosome regions. Inferred functions from genes within these regions suggest additional metabolic capabilities for the ST203 strains, particularly in carbohydrate utilization and metal ion transport. Additional ST203-unique metabolic genes include a riboflavin biosynthesis gene, dihydrofolate reductase and a fructose phosphotransferase system (PTS). PTS are numerous in both gram-positive and negative bacteria, and facilitate the transport, uptake and metabolism of carbohydrates. A recent functional study showed that deletion of E. faecium ptsD, which encodes a sugar-specific membrane-associated EIID subunit of a PTS gene cluster common to hospital isolates and absent in commensal isolates, compromises the ability of E. faecium to colonise the intestinal tract of mice under antibiotic treatment [39]. The results from this study and our observations here, showing two putative PTS loci present in all ST203 but absent from ST17 (Figure 2A), underscore the likely important contributions of PTS systems (loci beginning at Ef_aus0085_02768 and Ef_aus0085_02778), as well as other metabolic functions, in defining the success of a strain within a host and possibly the clinical environment.

Approximately $24 \%$ of the Aus0085-specific genes (relative to Aus0004 and TX16) are found on the six plasmids, highlighting the importance of these elements in shaping the Aus0085 genome and the potential for their transmission to other clinical E. faecium isolates. Aus0085_p1 possesses genes with predicted lactose functions that might allow for utilization of alternative carbohydrate sources. Enterococci in humans and other animals colonize the gastrointestinal tract and consequently, they compete with the gut microbiota for nutrients and resources $[1,40,41]$. The presence of additional metabolism genes might therefore confer a survival and growth advantage to ST203 in this environment. A functional genomic study recently conducted investigating carbohydrate metabolism in Streptococcus pneumoniae revealed a 20-minute increase in doubling time in a lactose PTS system mutant, suggesting that the additional lactose utilization pathway in Aus0085 might similarly promote the growth of ST203 [42]. Plasmid Aus0085_p3 possesses an intact version of the $a a d E$ and $a p h A$ genes, which confer resistance to streptomycin and kanamycin respectively. Streptomycin susceptibility testing revealed a 20-fold increase in the MIC of Aus0085 (1024 mg/L) compared to Aus0004 (48 mg/L). The aphA kanamycin resistance gene also confers resistance against gentamicin, which likely explains the high-level gentamicin resistance observed in Aus0085. Clinical isolates that exhibit high levels of resistance against gentamicin are often treated using streptomycin. Resistance against streptomycin in Aus0085, probably conferred by aadE, is therefore a concern.

The genome comparisons also revealed significant insights into the acquisition of the vancomycin resistanceconferring transposon in the representative genomes. Several transposons that are responsible for mediating $v a n B$-type resistance against vancomycin have previously been described in enterococci: $\operatorname{Tn} 1547, \operatorname{Tn} 1549$ and Tn5382. The $27 \mathrm{~kb}$ Tn5382 shares high sequence homology to the $34 \mathrm{~kb}$ Tn1549 [43-45]. Previous studies investigating the acquisition of vancomycin resistance have provided some clues to the sources and mode of transposon transmission, but there remains much to be 


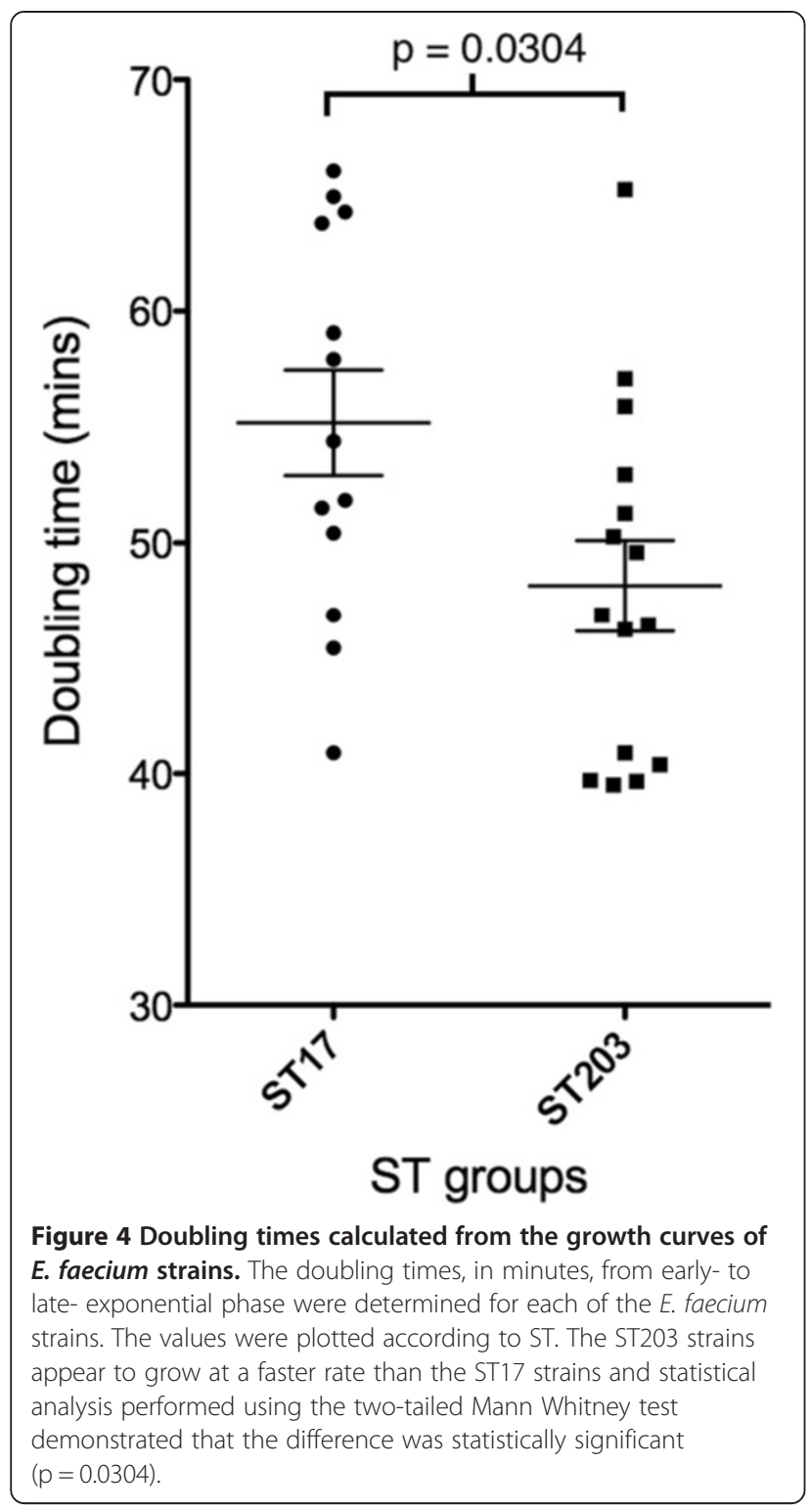

determined [46-48]. While vancomycin resistance in both Aus0004 and Aus0085 is conferred by the van operon associated with a Tn1549-like conjugative transposon, thorough transposon comparisons revealed substantial differences between the transposon length, sequence and site of insertion. The additional genes with a possible role in conjugation may consequently affect transposon transmission and spread. These variations show that Aus0004 and Aus0085 acquired their transposons from different donors. Non-synonymous nucleotide changes within the van locus coincide with the extent of vancomycin resistance in Aus0085, with antimicrobial susceptibility testing showing a 20-fold increase in the vancomycin MIC for Aus0085 compared to Aus0004. The E251G substitution within the histidine kinase domain of VanS and the C101F

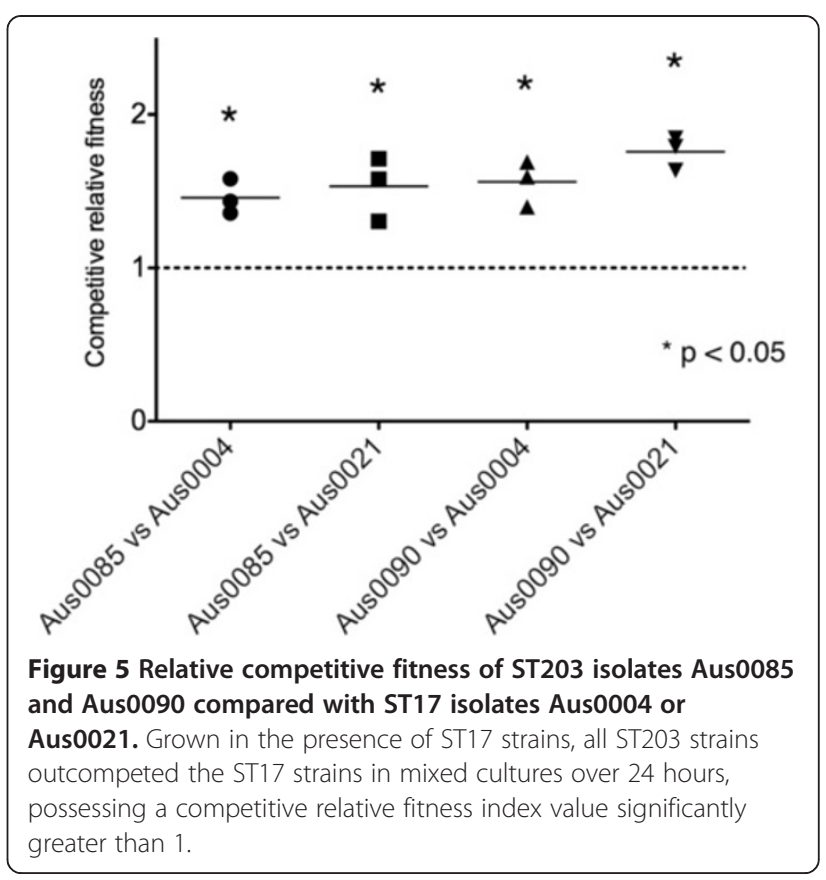

change within the $\mathrm{N}$-terminal substrate-binding domain of VanB are both candidates for further exploration to test their role in the increased resistance to vancomycin displayed by Aus0085.

The differences between the transposons in the ST17 and ST203 isolates not only relate to function but also provide important insight into the transmission and sources for acquisition of transposons in clinical $E$. faecium strains. The location of the van locus on mobile elements permits spread via horizontal gene transfer as well as clonal spread. It is important to establish the exact mechanisms that lead to the acquisition of antibiotic resistance, particularly in hospital-adapted strains, in order to understand the emergence of VRE and to prevent the spread of resistance to VSE or other bacterial species. While both Aus0004 and Aus0085 possess transposon insertion sites that differ from those previously described as preferred integration sites [47] (Figure 3), further analysis may reveal common insertion sites that distinguish the ST17 and ST203 isolates. Identifying these sources for transposon and vancomycin-resistance acquisition may potentially lead to diagnostic differences that can be exploited prevent VRE infection through the elimination of the sources.

We have also characterized some of the phenotypic differences between ST17 and ST203 E. faecium. The isolates we selected to study came from a previously described ST203 outbreak, which reported the displacement of resident ST17 E. faecium VRE with ST203. Given the significant number of additional metabolic genes in Aus0085, experiments assessing the rate of 


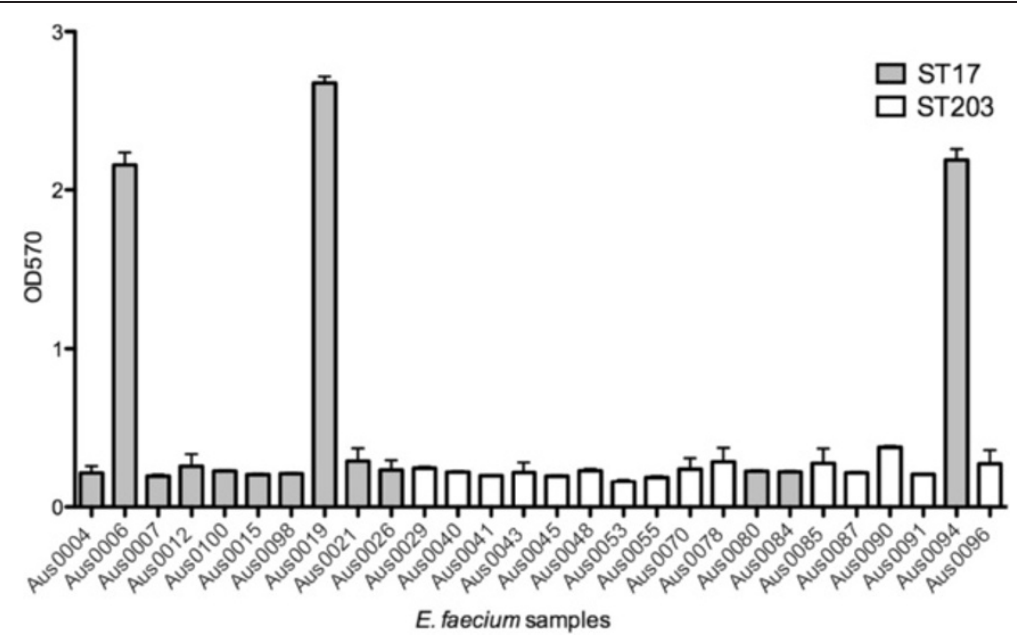

Figure 6 24-hour biofilm assays, performed in TSB supplemented with 1\% glucose. OD570nm readings were measured for each strain to determine the amount of biofilm formed. Isolates Aus0006, Aus0019 and Aus0094 exhibited significantly enhanced biofilm production compared to the other isolates $(p<0.001)$.

growth were performed to determine whether the additional genes yielded improved growth. Comparisons of 13 ST17 and 15 ST203 isolates highlighted significantly increased growth rates and competitive fitness for ST203 that may be factors contributing to the emergence of this clone in our hospital. Notably, Aus0004 possessed a prolonged lag phase compared to the other strains, and the delay in reaching exponential phase is likely to be due to its abnormal GC skew pattern arising from imbalanced replichores [22].
ST17 and ST203 comparisons of virulence using G. mellonella larvae demonstrated a range of virulence phenotypes in larvae inoculated with isolates from either clonal group. A potentially interesting difference was observed with the ST203 strains isolated from 2009 onwards, killing G. mellonella faster than earlier isolates of either sequence type. Genome comparisons however revealed few differences between the known virulence factors in Aus0004 and Aus0085. Both genomes contained genes encoding virulence factors such as hemolysin and
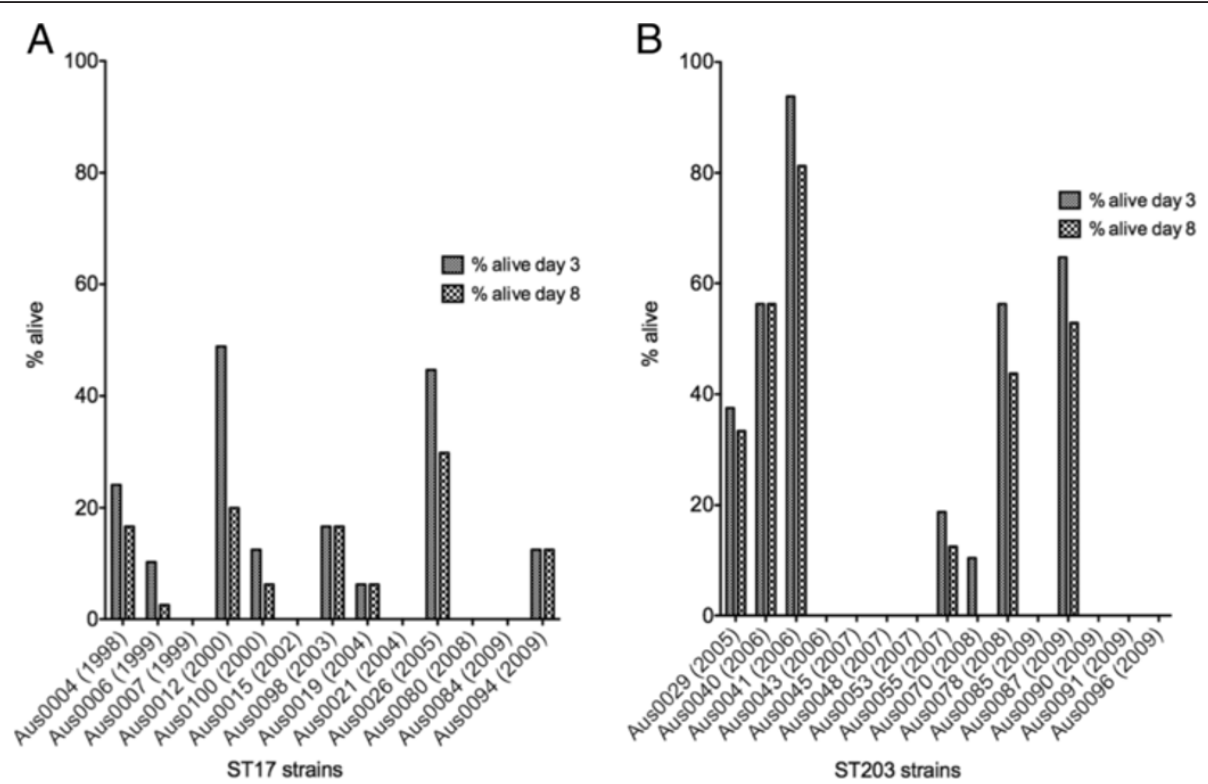

Figure 7 Galleria mellonella survival. Percentage of survival of larvae inoculated with a (A) ST17 E. faecium strain or (B) ST203 E. faecium strain at day 3 and day 8 . Both clonal groups possessed virulent strains that resulted in the death of all larvae by day 3 and avirulent strains that did not kill all the larvae by day 8 . 
enterococcal surface protein (esp). Esp appears very important for the ability of E. faecium to colonize the host [30,49-51]. Variations in its length, such as observed here, may alter function and explain the difference in $G$. mellonella virulence we observed between Aus0004 and Aus0085. Variation in Esp expression [30], as well as the potential of using the apparent variability of esp to discriminate between different ST17 and ST203 strains, were not explored here and remain to be investigated. We currently are trying to understand global differences in gene expression between Aus0004 and Aus0085 using RNAseq and the completed reference genomes.

\section{Conclusions}

The extent of variability between the three E. faecium genomes compared here highlights the significant roles played by mobile genetic elements in shaping the evolution of this species. The additional $502 \mathrm{~kb}$ in ST203 Aus0085 with genes that likely confer additional metabolic functions and antimicrobial resistances, help explain the emergence of this clone. These observations coincide with the, on average, faster growth and increased competitiveness of ST203 compared to ST17. While this study has provided several insights into differences that distinguish the ST17 from ST203 E. faecium strains, differences in the expression of particular genes also require investigation. In this respect, the completed Aus0085 genome represents an important resource as a reference for read-mapping applications such asRNAseq for exploring the E. faecium transcriptome, or for high-resolution molecular epidemiology to better understand the factors behind the emergence of this opportunistic nosocomial pathogen.

\section{Methods}

\section{Bacterial sequences and strains}

The strains used in this study were selected from isolates previously reported [14] to represent the ST17 and ST203 E. faecium strains collected over a 12-year period from bacteraemia patients at the Austin Hospital (Table 2). Bacterial cultures were prepared in brain heart infusion (BHI) broth unless otherwise stated.

\section{Antimicrobial susceptibility testing}

Antimicrobial susceptibility tests determining the MICs against vancomycin and streptomycin were performed for isolates Aus0004 and Aus0085 by Macromethod Etest.

\section{Genome sequencing and assembly}

Genomic DNA was sequenced on a 454 GS FLX instrument using a $3 \mathrm{kbp}$ mate-pair library yielding $100 \mathrm{~K}$ reads of average length 402-bp (Roche Diagnostics, Basel, Switzerland), and on an Illumina GAIIx using a paired-end library yielding $12 \mathrm{M}$ reads of length $36-\mathrm{bp}$. The 454 reads were de novo assembled using Newbler (v2.6). The Illumina reads were used to correct errors in the Newbler scaffolds. Finishing was managed with Gap4, using combinations of PCR, primer walking and sequencing of selected clones from a 50-kb insert-size E. coli bacterial artificial chromosome (BAC) E. faecium Aus0085 clone library. Correct assembly was validated by reference to a previously described NcoI Optical Map (Opgen) [14].

\section{Genome analysis}

Genome annotation of E. faecium Aus0085 was performed using the in-house tools Prokka and Wasabi (http://www. bioinformatics.net.au). Comparison of whole chromosome DNA sequences for E. faecium isolates Aus0004, Aus0085 and TX16 were compared using the Artemis Comparison Tool (ACT), Mauve (v2.3.1) and BLAST Ring Image Generator (BRIG) [52-55]. Mobile genetic elements such as insertion sequence elements (ISEs) and phage regions were identified using the genome annotation, ISfinder and Phast [56,57]. CRISPRfinder was used to screen for the presence of CRISPR elements [58].

\section{Multi-isolate comparative genomics}

Through a larger, separate study examining VRE transmission, $2 \times 100$ bp paired-end Illumina sequence reads were available for the 26 isolates listed in Table 2 (Howden et al., submitted). These reads were aligned separately to the completed Aus0085 genome using SHRiMP 2.0 [59]. Those positions in Aus0085 that were covered by at least one read from every genome defined a core genome. Read-mapping outputs were visualized in Artemis. SNPs were identified using Nesoni v0.35, a Python utility that uses the sequence reads for each genome aligned to the core genome to construct a tally of putative differences at each nucleotide position (including substitutions, insertions, and deletions). This tally was then used in a Bayesian model to decide whether a base or deletion could be called for the position, and if so, whether it differed from the reference sequence (www.bioinformatics.net.au). Phylogenetic analyses were performed using a distance method, based on pairwise nucleotide sequence alignments for the core genome among all isolates. Split decomposition and Neighbour-joining analysis was employed using uncorrected $\mathrm{p}$ distances as implemented in SplitsTree4 [60]. The reads from these 26 isolates were also subject to de novo assembly using Velvet (v1.2.04) [61] and annotation with Prokka. The resulting protein-coding DNA sequences (CDS) were used as for ortholog clustering analysis. Ortholog clustering was performed using derived amino acid sequences for each CDS in CD-HIT v4.6 (default parameters) [62], with the clustering requirement that specific sets have representatives in all their genomes related to that set. The sets were defined as 'core genes present in all ST17 and ST203', 'ST203-specific genes' and 'ST17-specific genes'). 


\section{Nucleotide accession numbers}

The complete genome sequence and annotation for E. faecium Aus0085 has been deposited in GenBank under Bioproject ID PRJNA193299 and accession numbers CP006620-CP006626.

\section{Growth curves}

Growth curves were generated for the E. faecium strains by adding a $100 \mu \mathrm{l}$ 1:100 dilution of overnight culture, prepared in BHI broth, to individual wells in a 96-well flat-bottom plate and incubated over a 24-hour period at $37^{\circ} \mathrm{C}$. Starting from time point $0, \mathrm{OD}_{600 \mathrm{~nm}}$ measurements were made at hourly intervals over a 24 -hour period. The generation and doubling times were determined for each of the strains during a 2 hour period during exponential phase of growth according to the following formulas: Generation time $(\mathrm{GT})$, in mins $=\left(\log \mathrm{N}_{\mathrm{t}}-\log \mathrm{N}_{0}\right) \div \log 2$, $\mathrm{N}_{\mathrm{t}}=\mathrm{OD}$ value at end of exponential period, $\mathrm{N}_{0}=\mathrm{OD}$ value at beginning of exponential period, Doubling time $(\mathrm{DT})$, in mins $=(\Delta \mathrm{t} \div \mathrm{GT}) \times 60, \Delta \mathrm{t}=2$ hours Growth curve experiments were repeated three times.

\section{Competition growth assays}

For each experiment, a 1:200 dilution of an overnight culture from ST17 isolates Aus0004 or Aus0021 (low level resistance to gentamicin, $\mathrm{MIC}=6 \mathrm{mg} / \mathrm{L}$ ) and ST203 isolates Aus0085 or Aus0090 (high level resistance to gentamicin, MIC $>1024 \mathrm{mg} / \mathrm{L}$ ) were separately added to $50 \mathrm{~mL} \mathrm{BHI}$ broth and incubated over a 24-hour period at $37^{\circ} \mathrm{C}$. Starting from time point $0,1 \mathrm{~mL}$ samples were taken at hourly intervals for OD600nm measurements until a constant reading was attained and again at time point $24 \mathrm{~h}$. The ratio of ST17 colonies to ST203 colonies was determined by plating $100 \mu \mathrm{l}$ of the serial dilutions prepared from the samples on $\mathrm{BHI}$ agar and $\mathrm{BHI}$ agar with $100 \mathrm{mg} / \mathrm{L}$ gentamicin. To analyse the relative fitness of the ST203 strain compared to the ST17 strain when grown together under experimental conditions, the following formula was used to calculate the Relative Competitive Fitness Index (RCFI): RCFI $=[\ln$ (number of ST203 colonies at 24 hours $\div$ number of ST203 colonies at 0 hours $)] \div[\ln$ (number of ST17 colonies at 24 hours $\div$ number of ST17 colonies at 0 hours)] [63] Each competition growth assay experiment was repeated at least three times. Statistical significance of the differences between the sample means compared to a threshold value of 1.0 were assessed using one sample $t$-test.

\section{Biofilm assays}

Overnight cultures were prepared using tryptic soy broth (TSB) supplemented with $1 \%$ glucose. 96-well polystyrene flat-bottom microtitre plates were coated with $200 \mu \mathrm{l}$ 1:200 diluted E. faecium overnight culture in TSB with 1\% glucose. Following a 24-hour stationary incubation period at $37^{\circ} \mathrm{C}$, the plates were washed with phosphate buffered saline (PBS), stained with $125 \mu \mathrm{l} 0.1 \% \mathrm{w} / \mathrm{v}$ crystal violet, and left at room temperature for 10 minutes. The plates were then washed with PBS and left to dry for a further 10 minutes before the addition of $125 \mu \mathrm{l}$ 80:20 ethanol acetone. Absorbance measurements at OD570nm were determined for each well. Experiments were repeated an additional two times.

\section{Galleria mellonella time kill assays}

The virulence of the E. faecium strains was assessed using a previously described Galleria mellonella (Greater Wax Moth) invertebrate infection model that has been utilized in several studies as an invertebrate model to study the virulence of pathogenic organisms including Staphylococcus aureus and Enterococcus faecalis [64-66]. In brief, G. mellonella larvae in the final instar were inoculated in groups of 16 with a particular $E$. faecium isolate. Bacterial suspensions for each isolate were prepared by washing cells with PBS that were harvested from overnight cultures. Ten microliters of the bacterial suspension, comprised of approximately $0.5-1.0 \times 10^{9} \mathrm{CFU} / \mathrm{mL}$, was injected into the hamocoel via the first right proleg of each larva. The bacterial suspensions from which the inoculums were taken were plated onto $\mathrm{BHI}$ agar in duplicates to check the starting cell concentration. Following injection, the larvae were incubated at $37^{\circ} \mathrm{C}$ and the number of dead larvae were recorded daily. The number of bacteria in the larvae at time of death was quantified. This quantification was achieved by plating serial dilutions of the hemolymph onto BHI agar. The assays were repeated in biological triplicates (three different bacterial suspensions), and control groups with larvae inoculated with PBS were included. The percentage of survival at days 3 and 8 was calculated for each strain.

\section{Ethics statement}

This study was performed in accordance with Austin Health Human Research Ethics Committee guidelines. The use of de-identified bacterial strains described in this manuscript, and the study of the bacterial isolates and not human subjects, meant that formal Human Ethics Committee approval or Informed Patient Consent was not required.

\section{Additional files}

Additional file 1: Table S1. Complete list of CDS unique to Aus0085 based on comparison to Aus0004.

Additional file 2: Table S2. ST17 and ST203 'unique' genes based on comparison of 13 ST17 and 15 ST203 genome sequences. 
Additional file 3: Figure S1. Individual Kaplan Meier survival curves generated by ST17 Enterococcus faecium isolates in Galleria mellonella time-kill virulence assays.

Additional file 4: Figure S2. Individual Kaplan Meier survival curves generated by ST203 Enterococcus faecium isolates in Galleria mellonella time-kill virulence assays.

\section{Abbreviations}

ACT: Artemis comparison tool; AGAR: Australian group on antimicrobial resistance; BAC: Bacterial artificial chromosome; BHI: Brain heart infusion; BRIG: BLAST ring image generator; CC17: Clonal complex 17; CDS: Coding sequence(s); DT: Doubling time; GT: Generation time; ISE: Insertion sequence element; MIC: Minimal inhibitory concentration; MLST: Multi-locus sequence typing; PBS: Phosphate buffered saline; PFGE: Pulsed field gel electrophoresis; PTS: Phosphoenolpyruvate:carbohydrate phosphotransferase system(s); RCFI: Relative competitive fitness index; ST: Sequence type; ST17: Sequence type 17; ST203: Sequence type 203; TSB: Tryptic soy broth; VRE: Vancomycinresistant enterococci; VREfm: Vancomycin-resistant Enterococcus faecium; VSE: Vancomycin-susceptible enterococci.

\section{Competing interests}

The authors declare that they have no competing interests.

\section{Authors' contributions}

MMCL designed and performed experiments, analysed data and co-wrote the paper, TS, NJT, SB, MLG, and PDRJ analysed data, HC, VH and RJM performed experiments, BPH and TPS designed the study, analysed data and co-wrote the paper. All authors read and approved the final manuscript.

\section{Authors' information}

Benjamin P Howden and Timothy P Stinear are joint senior author.

\section{Acknowledgements}

We thank Elizabeth Grabsch and Shirley Xie for assistance with initial characterization of the strains used in this study. This research was supported by a grant from the National Health and Medical Research Council of Australia.

\section{Author details}

'Department of Microbiology and Immunology, University of Melbourne, Parkville 3010, Victoria, Australia. ${ }^{2}$ Victorian Bioinformatics Consortium, Monash University, Clayton, Victoria 3800, Australia. ${ }^{3}$ Australian Animal Health Laboratory, CSIRO, Geelong, Victoria 3220, Australia. ${ }^{4}$ ARC Centre of Excellence in Structural and Functional Microbial Genomics, Clayton, Victoria, Australia. ${ }^{5}$ Austin Centre for Infection Research (ACIR), Infectious Diseases Department, Austin Health, Heidelberg, Victoria 3084, Australia. ${ }^{6}$ Department of Medicine, University of Melbourne, Heidelberg, Victoria 3084, Australia. ${ }^{7}$ Microbiology Department, Austin Health, Heidelberg, Victoria 3084, Australia. ${ }^{8}$ Department of Microbiology, Monash University, Clayton, Victoria 3800, Australia.

Received: 19 March 2013 Accepted: 28 August 2013

Published: 1 September 2013

\section{References}

1. Fisher K, Phillips C: The ecology, epidemiology and virulence of Enterococcus. Microbiology 2009, 155(Pt 6):1749-1757.

2. Courvalin P: Vancomycin resistance in gram-positive cocci. Clin Infect Dis 2006, 42(Suppl 1):S25-S34.

3. Kelesidis T, Humphries R, Uslan DZ, Pegues DA: Daptomycin nonsusceptible enterococci: an emerging challenge for clinicians. Clin Infect Dis 2011, 52(2):228-234.

4. Cetinkaya Y, Falk P, Mayhall CG: Vancomycin-resistant enterococci. Clin Microbiol Rev 2000, 13(4):686-707.

5. Clewell DB: Movable genetic elements and antibiotic resistance in enterococci. Eur J Clin Microbiol Infect Dis 1990, 9(2):90-102.

6. Xu X, Lin D, Yan G, Ye X, Wu S, Guo Y, Zhu D, Hu F, Zhang Y, Wang F, et al: vanM, a new glycopeptide resistance gene cluster found in Enterococcus faecium. Antimicrob Agents Chemother 2010, 54(11):4643-4647.
7. Boyd DA, Willey BM, Fawcett D, Gillani N, Mulvey MR: Molecular characterization of Enterococcus faecalis N06-0364 with low-level vancomycin resistance harboring a novel D-Ala-D-Ser gene cluster, vanL. Antimicrob Agents Chemother 2008, 52(7):2667-2672.

8. Lebreton F, Depardieu F, Bourdon N, Fines-Guyon M, Berger P, Camiade S, Leclercq R, Courvalin P, Cattoir V: D-Ala-d-Ser VanN-type transferable vancomycin resistance in Enterococcus faecium. Antimicrob Agents Chemother 2011, 55(10):4606-4612.

9. Iwen PC, Kelly DM, Linder J, Hinrichs SH, Dominguez EA, Rupp ME, Patil KD: Change in prevalence and antibiotic resistance of Enterococcus species isolated from blood cultures over an 8-year period. Antimicrob Agents Chemother 1997, 41(2):494-495.

10. Mundy LM, Sahm DF, Gilmore M: Relationships between enterococcal virulence and antimicrobial resistance. Clin Microbiol Rev 2000, 13(4):513-522

11. Metan G, Zarakolu P, Unal S: Rapid detection of antibacterial resistance in emerging Gram-positive cocci. J Hosp Infect 2005, 61(2):93-99.

12. Endtz HP, van den Braak N, Verbrugh HA, van Belkum A: Vancomycin resistance: status quo and quo vadis. Eur J Clin Microbiol Infect Dis 1999, 18(10):683-690.

13. Kamarulzaman A, Tosolini FA, Boquest J, Geddes JE, Richards MJ: Vancomycin- resistant Enterococcus faecium in a liver transplant recipient. ANZ J Med 1995, 25:560.

14. Johnson PD, Ballard SA, Grabsch EA, Stinear TP, Seemann T, Young HL, Grayson ML, Howden BP: A sustained hospital outbreak of vancomycin-resistant Enterococcus faecium bacteremia due to emergence of vanB E. faecium sequence type 203. J Infect Dis 2010, 202(8):1278-1286

15. Bell JM, Paton JC, Turnidge J: Emergence of vancomycin-resistant enterococci in Australia: phenotypic and genotypic characteristics of isolates. J Clin Microbiol 1998, 36(8):2187-2190.

16. Homan WL, Tribe D, Poznanski S, Li M, Hogg G, Spalburg E, Van Embden JD Willems RJ: Multilocus sequence typing scheme for Enterococcus faecium. J Clin Microbiol 2002, 40(6):1963-1971

17. Turabelidze D, Kotetishvili M, Kreger A, Morris JG Jr, Sulakvelidze A: Improved pulsed-field gel electrophoresis for typing vancomycin-resistant enterococci. J Clin Microbiol 2000, 38(11):4242-4245.

18. Top J, Willems R, Bonten M: Emergence of CC17 Enterococcus faecium: from commensal to hospital-adapted pathogen. FEMS Immunol Med Microbiol 2008, 52(3):297-308.

19. Bonten MJ, Willems R, Weinstein RA: Vancomycin-resistant enterococci: why are they here, and where do they come from? Lancet Infect Dis 2001, 1(5):314-325.

20. Hegstad K, Mikalsen T, Coque TM, Werner G, Sundsfjord A: Mobile genetic elements and their contribution to the emergence of antimicrobial resistant Enterococcus faecalis and Enterococcus faecium. Clin Microbiol Infect 2010, 16(6):541-554.

21. Antimicrobial susceptibility and vancomycin resistant enterococci (VRE) characterisation report: 2010. http://www.agargroup.org/surveys.

22. Lam MM, Seemann T, Bulach DM, Gladman SL, Chen H, Haring V, Moore RJ, Ballard S, Grayson ML, Johnson PD, et al: Comparative analysis of the first complete Enterococcus faecium genome. J Bacteriol 2012, 194(9):2334-2341.

23. Qin X, Galloway-Pena JR, Sillanpaa J, Roh JH, Nallapareddy SR, Chowdhury S, Bourgogne A, Choudhury T, Muzny DM, Buhay CJ, et al: Complete genome sequence of Enterococcus faecium strain TX16 and comparative genomic analysis of Enterococcus faecium genomes. BMC Microbiol 2012, 12:135.

24. Rudy CK, Scott JR: Length of the coupling sequence of Tn916. J Bacteriol 1994, 176(11):3386-3388.

25. Garcia-Migura L, Hasman H, Jensen LB: Presence of pRI1: a small cryptic mobilizable plasmid isolated from Enterococcus faecium of human and animal origin. Curr Microbio/ 2009, 58(2):95-100.

26. Werner G, Hildebrandt B, Witte W: Aminoglycoside-streptothricin resistance gene cluster aadE-sat4-aphA-3 disseminated among multiresistant isolates of Enterococcus faecium. Antimicrob Agents Chemother 2001, 45(11):3267-3269.

27. Hugenholtz J, Perdon L, Abee T: Growth and energy generation by Lactococcus lactis subsp. lactis biovar diacetylactis during citrate metabolism. Appl Environ Microbiol 1993, 59(12):4216-4222.

28. Blancato VS, Repizo GD, Suarez CA, Magni C: Transcriptional regulation of the citrate gene cluster of Enterococcus faecalis involves the GntR family transcriptional activator CitO. J Bacterio/ 2008, 190(22):7419-7430. 
29. Heikens E, Singh KV, Jacques-Palaz KD, van Luit-Asbroek M, Oostdijk EA, Bonten MJ, Murray BE, Willems RJ: Contribution of the enterococcal surface protein Esp to pathogenesis of Enterococcus faecium endocarditis. Microbes Infect 2011, 13(14-15):1185-1190.

30. Top J, Paganelli FL, Zhang X, van Schaik W, Leavis HL, van Luit-Asbroek M, van der Poll T, Leendertse M, Bonten MJ, Willems RJ: The Enterococcus faecium enterococcal biofilm regulator, EbrB, regulates the esp operon and is implicated in biofilm formation and intestinal colonization. Plos One 2013, 8(5):e65224.

31. Garneau S, Martin NI, Vederas JC: Two-peptide bacteriocins produced by lactic acid bacteria. Biochimie 2002, 84(5-6):577-592.

32. Hechard Y, Sahl HG: Mode of action of modified and unmodified bacteriocins from gram-positive bacteria. Biochimie 2002, 84(5-6):545-557.

33. Donelli G, Guaglianone E: Emerging role of Enterococcus spp in catheterrelated infections: biofilm formation and novel mechanisms of antibiotic resistance. J Vasc Access 2004, 5(1):3-9.

34. Donlan RM: Biofilms: microbial life on surfaces. Emerg Infect Dis 2002, 8(9):881-890.

35. Donlan RM, Costerton JW: Biofilms: survival mechanisms of clinically relevant microorganisms. Clin Microbiol Rev 2002, 15(2):167-193.

36. Sagel U, Schulte B, Heeg P, Borgmann S: Vancomycin-resistant enterococci outbreak, Germany, and calculation of outbreak start. Emerg Infect Dis 2008, 14(2):317-319.

37. Xu HT, Tian R, Chen DK, Xiao F, Nie ZY, Hu YJ, Zhang XZ, Li JM: Nosocomial spread of hospital-adapted CC17 vancomycin-resistant Enterococcus faecium in a tertiary-care hospital of Beijing, China. Chin Med J (Engl) 2011, 124(4):498-503.

38. Willems RJ, Top J, van Schaik W, Leavis H, Bonten M, Siren J, Hanage WP, Corander J: Restricted gene flow among hospital subpopulations of Enterococcus faecium. MBio 2012, 3(4):e00151-00112.

39. Zhang $X$, Top J, de Been M, Bierschenk D, Rogers $M$, Leendertse M, Bonten MJ, van der Poll T, Willems RJ, van Schaik W: Identification of a genetic determinant in clinical Enterococcus faecium strains that contributes to intestinal colonization during antibiotic treatment. J Infect Dis 2013, 207(11):1780-1786.

40. Coleman ME, Dreesen DW, Wiegert RG: A simulation of microbial competition in the human colonic ecosystem. Appl Environ Microbiol 1996, 62(10):3632-3639.

41. Ushijima T, Seto A: Selected faecal bacteria and nutrients essential for antagonism of Salmonella typhimurium in anaerobic continuous flow cultures. J Med Microbiol 1991, 35(2):111-117.

42. Bidossi A, Mulas L, Decorosi F, Colomba L, Ricci S, Pozzi G, Deutscher J, Viti C, Oggioni MR: A functional genomics approach to establish the complement of carbohydrate transporters in Streptococcus pneumoniae. Plos one 2012, 7(3):e33320.

43. Garnier F, Taourit S, Glaser P, Courvalin P, Galimand M: Characterization of transposon Tn1549, conferring VanB-type resistance in Enterococcus spp. Microbiology 2000, 146(Pt 6):1481-1489.

44. Carias LL, Rudin SD, Donskey CJ, Rice LB: Genetic linkage and cotransfer of a novel, vanB-containing transposon (Tn5382) and a low-affinity penicillin-binding protein 5 gene in a clinical vancomycin-resistant Enterococcus faecium isolate. J Bacteriol 1998, 180(17):4426-4434.

45. Quintiliani R Jr, Courvalin P: Characterization of Tn1547, a composite transposon flanked by the IS16 and IS256-like elements, that confers vancomycin resistance in Enterococcus faecalis BM4281. Gene 1996, 172(1):1-8.

46. Willems RJ, Top J, van den Braak N, van Belkum A, Mevius DJ, Hendriks G, van Santen-Verheuvel M, van Embden JD: Molecular diversity and evolutionary relationships of Tn1546-like elements in enterococci from humans and animals. Antimicrob Agents Chemother 1999, 43(3):483-491.

47. Launay A, Ballard SA, Johnson PD, Grayson ML, Lambert T: Transfer of vancomycin resistance transposon Tn1549 from Clostridium symbiosum to Enterococcus spp. in the gut of gnotobiotic mice. Antimicrob Agents Chemother 2006, 50(3):1054-1062

48. Tsvetkova K, Marvaud JC, Lambert T: Analysis of the mobilization functions of the vancomycin resistance transposon Tn1549, a member of a new family of conjugative elements. J Bacterio/ 2010, 192(3):702-713.

49. Heikens E, Bonten MJ, Willems RJ: Enterococcal surface protein Esp is important for biofilm formation of Enterococcus faecium E1162. J Bacteriol 2007, 189(22):8233-8240.
50. Heikens $E$, Leendertse M, Wijnands LM, van Luit-Asbroek M, Bonten MJ, van der Poll T, Willems RJ: Enterococcal surface protein Esp is not essential for cell adhesion and intestinal colonization of Enterococcus faecium in mice. BMC Microbiol 2009, 9:19.

51. Leendertse M, Heikens E, Wijnands LM, van Luit-Asbroek M, Teske GJ, Roelofs JJ, Bonten MJ, van der Poll T, Willems RJ: Enterococcal surface protein transiently aggravates Enterococcus faecium-induced urinary tract infection in mice. J Infect Dis 2009, 200(7):1162-1165.

52. Carver TJ, Rutherford KM, Berriman M, Rajandream MA, Barrell BG, Parkhill J: ACT: the artemis comparison tool. Bioinformatics 2005, 21(16):3422-3423.

53. Alikhan NF, Petty NK, Ben Zakour NL, Beatson SA: BLAST ring image generator (BRIG): simple prokaryote genome comparisons. BMC genomics 2011, 12:402.

54. Darling AC, Mau B, Blattner FR, Perna NT: Mauve: multiple alignment of conserved genomic sequence with rearrangements. Genome Res 2004 14(7):1394-1403.

55. Darling AE, Mau B, Perna NT: Progressive mauve: multiple genome alignment with gene gain, loss and rearrangement. PloS one 2010, 5(6):e11147.

56. Zhou Y, Liang Y, Lynch KH, Dennis JJ, Wishart DS: PHAST: a fast phage search tool. Nucleic Acids Res 2011, 39(Web Server issue):W347-W352.

57. Siguier P, Perochon J, Lestrade L, Mahillon J, Chandler M: ISfinder: the reference centre for bacterial insertion sequences. Nucleic Acids Res 2006, 34(Database issue):D32-D36.

58. Grissa I, Vergnaud G, Pourcel C: CRISPRFinder: a web tool to identify clustered regularly interspaced short palindromic repeats. Nucleic Acids Res 2007, 35(Web Server issue):W52-W57.

59. David M, Dzamba M, Lister D, llie L, Brudno M: SHRiMP2: sensitive yet practical short read mapping. Bioinformatics 2011, 27(7):1011-1012.

60. Huson DH: SplitsTree: analyzing and visualizing evolutionary data. Bioinformatics 1998, 14(1):68-73.

61. Zerbino DR, Birney E: Velvet: algorithms for de novo short read assembly using de Bruijn graphs. Genome Res 2008, 18(5):821-829.

62. Fu L, Niu B, Zhu Z, Wu S, Li W: CD-HIT: accelerated for clustering the next-generation sequencing data. Bioinformatics 2012, 28(23):3150-3152.

63. Bhatter $P$, Chatterjee A, D'Souza D, Tolani M, Mistry N: Estimating fitness by competition assays between drug susceptible and resistant Mycobacterium tuberculosis of predominant lineages in Mumbai, India. PloS one 2012, 7(3):e33507.

64. Park SY, Kim KM, Lee JH, Seo SJ, Lee $H$ : Extracellular gelatinase of Enterococcus faecalis destroys a defense system in insect hemolymph and human serum. Infect Immun 2007, 75(4):1861-1869.

65. Peleg AY, Monga D, Pillai S, Mylonakis E, Moellering RC Jr, Eliopoulos GM: Reduced susceptibility to vancomycin influences pathogenicity in Staphylococcus aureus infection. J Infect Dis 2009, 199(4):532-536.

66. Lebreton F, Le Bras F, Reffuveille F, Ladjouzi R, Giard JC, Leclercq R, Cattoir V: Galleria mellonella as a model for studying Enterococcus faecium host persistence. J Mol Microbiol Biotechnol 2011, 21(3-4):191-196.

doi:10.1186/1471-2164-14-595

Cite this article as: Lam et al:: Comparative analysis of the complete genome of an epidemic hospital sequence type 203 clone of vancomycin-resistant Enterococcus faecium. BMC Genomics 2013 14:595.

\section{Submit your next manuscript to BioMed Central and take full advantage of:}

- Convenient online submission

- Thorough peer review

- No space constraints or color figure charges

- Immediate publication on acceptance

- Inclusion in PubMed, CAS, Scopus and Google Scholar

- Research which is freely available for redistribution 